\title{
Design an Extended Circular Planar Microstrip Patch Antenna for UWB Application
}

\author{
Tarun Dadheech \\ Electronics \& Communication \\ Bhagwant University \\ Ajmer
}

\author{
Chandraveer Singh \\ Electronics \& Communication \\ Bhagwant University \\ Ajmer
}

\author{
Ajay Dadhich \\ Electronics Inst. \& Control \\ Govt. Engineering College \\ Ajmer
}

\begin{abstract}
The aim of this paper is to design and simulation the Microstrip Patch Antenna which covers the Ultra Wide Band 3.1 to $10.6 \mathrm{GHz}$. This paper covers study of basics and fundamentals of Microstrip patch antenna. The various parameters of the antenna are the dimensions of the patch and ground planes and the separation between them and this antenna is fabricated using an $\mathrm{h}=1.6 \mathrm{~mm}$ thick FR4 substrate $\left(\varepsilon_{\mathrm{r}}=4.4\right)$, which occupies a coverage area of $26.6 \mathrm{Ws} \times 29.3$ Ls $\mathrm{mm}^{2}$.This is a simulation based study. The design and simulation of the antenna is carried out using CST microwave Studio simulation software. This design is Extended Circular Planar Microstrip Patch Antenna that uses defected ground plane which covers the entire UWB range. Return loss curve, antenna gains and the Far field results are shown for designed antenna. The proposed antenna has return loss of $-70 \mathrm{db}$ at $3.8 \mathrm{GHz}$ frequency with VSWR $=1.0006835$, impedance bandwidth of approx. $9 \mathrm{GHz}$ from $3 \mathrm{GHz}$ to $12 \mathrm{GHz}$ at UWB range.
\end{abstract}

\section{Keywords}

Flame Retardant 4(FR4), Ultra Wide Band (UWB), Computer Simulation Technology (CST), Computer Aided Design (CAD).

\section{INTRODUCTION}

These day's the wireless system has become a part of human life. Antennas are our electronics eyes and ears on the world. They are our links with space. They are essential, integral part of our civilization [11]. Antenna is an electrical device which transmits the electromagnetic waves into the space by converting the electric power given at the input into the radio waves and at the receiver side the antenna intercepts these radio waves and converts them back into the electrical power [10].

Microstrip antennas became very popular in the 1970s primarily for space borne applications. These antennas consist of a metallic patch on a grounded substrate. The metallic patch can take many different configurations. However, the rectangular and circular are the most popular because of ease of analysis and fabrication and their attractive radiation characteristics, especially low cross polarization radiation [9]. A Microstrip antenna is one who offers low profile and light weight. It is a wide beam narrowband antenna can be manufactured easily by the printed circuit technology such as a metallic layers in a particular shape is bonded on a dielectric substrate which forms a radiating element and another continuous metallic layer on the other side of substrate as ground plane. Instead of using dielectric substrate some of the Microstrip antennas use dielectric spacers which results in wider bandwidth but in the cost of less ruggedness [1]. The size of Microstrip antenna is related to the wavelength of operation generally $\lambda / 2$. The applications of Microstrip antennas are above the microwave frequency because below this frequency the use of Microstrip antenna doesn't make a sense because of the size of antenna. At frequencies lower than microwave, Microstrip patches don't make sense because of the sizes required. These antennas can be mounted on the surface of the high performance aircraft, space craft, satellites, missiles, cars and even handheld mobile telephones.

\section{ANTENNA DESIGN EXTENDED CIRCULAR PLANAR ANTENNA FOR UWB APPLICATION}

The proposed antenna parameters are shown in the figure. The Design consists of a half circular patch which is extended to an extra length. The Antenna is fabricated on FR-4 material with thickness $\mathrm{h}=1.6 \mathrm{~mm}$ and Microstrip feed line $(50 \Omega)$ is used for feeding. A circular shape partial ground plane is used with an elliptical notch just below the feed line. The simulation results show that the antenna fulfills the requirement of UWB range.

The front and back view of the proposed antenna is shown in Fig.1 \& Fig.2. Partial ground plane with curvy edges is used. Making an elliptical notch behind the feed line in ground plane and narrow rectangular slit in ground results in drastically improvement in the return loss curve. This is a simulation based study. The design and simulation of the antenna is carried out using CST microwave Studio simulation software.

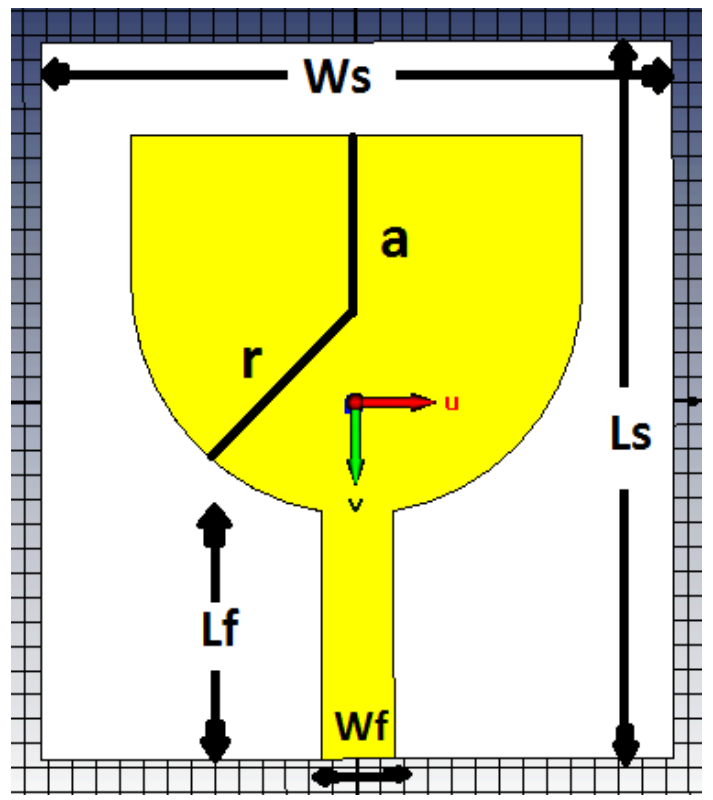

Figure 1: Front view of proposed antenna by CST Software 


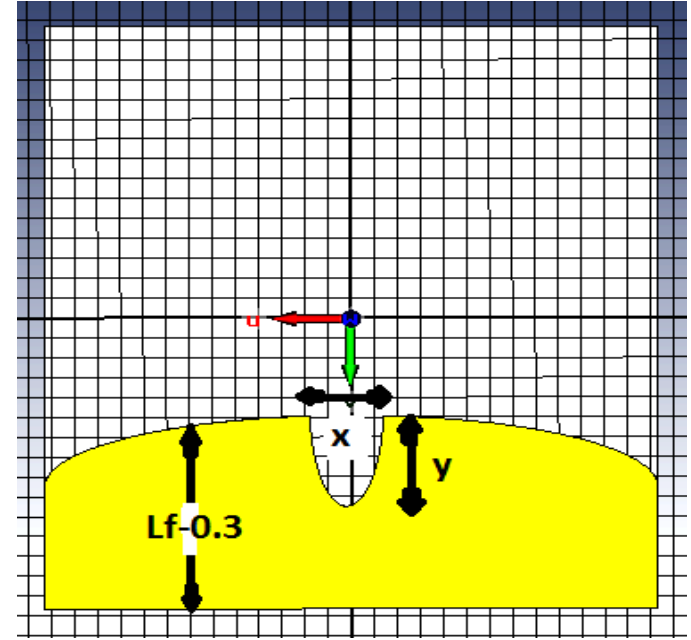

Figure 2: Back view of proposed antenna by CST Software

\subsection{Antenna Parameters}

Parameter list with their values are written in the table .1. All the dimensions are in millimeter.

Table 1: Dimension of proposed antenna design

\begin{tabular}{|c|c|c|}
\hline Parameter & Description & Value (mm) \\
\hline $\mathrm{r}$ & Radius circular patch & 9.5 \\
\hline $\mathrm{a}$ & Patch Extension & 6 \\
\hline $\mathrm{x}$ & X radius of elliptical notch & 1.5 \\
\hline Lf & Y radius of elliptical notch & 3 \\
\hline Wf & Length of feed line & 10 \\
\hline Ws & Width of feed line & 3.015 \\
\hline Ls & Length of substrate & 26.3 \\
\hline
\end{tabular}

\section{SIMULATION RESULTS}

The S11 vs. frequency curve with the optimized values is shown below. The return loss curve shows that the antenna has bandwidth from $3 \mathrm{GHz}$ to $12 \mathrm{GHz}$ with a minimum $\mathrm{S} 11$ $70 \mathrm{~dB}$ at $3.8 \mathrm{GHz}$. This shows that the proposed antenna covers the entire UWB.

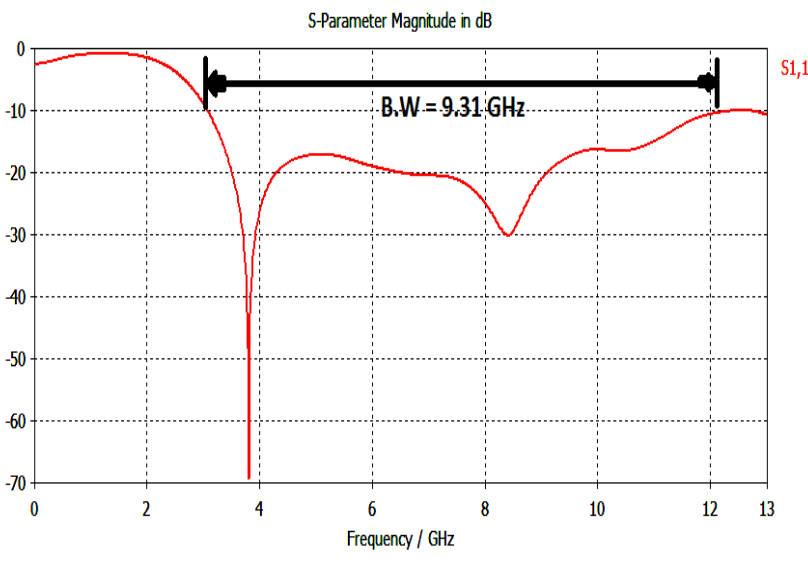

Figure 3: Return loss vs. frequency curve of proposed antenna.

The VSWR vs. frequency curve for the proposed antenna with Optimized parameters are shown below. The VSWR for the proposed antenna is 1 that resemble with ideal value of VSWR.

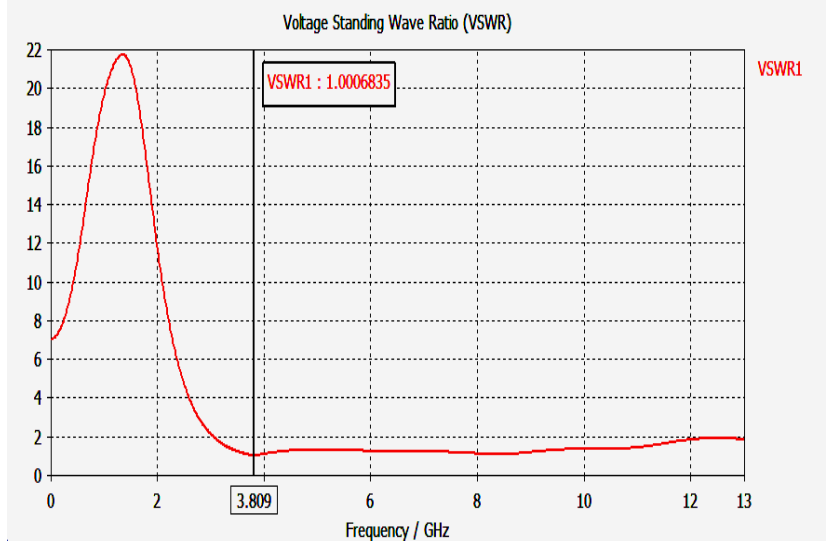

Figure 4: Voltage Standing Wave Ratio Curve

Radiation pattern with principal E-plane and H-plane for the different frequencies are shown in figure.

\section{Farfield Directivity Abs (Phi=90)}

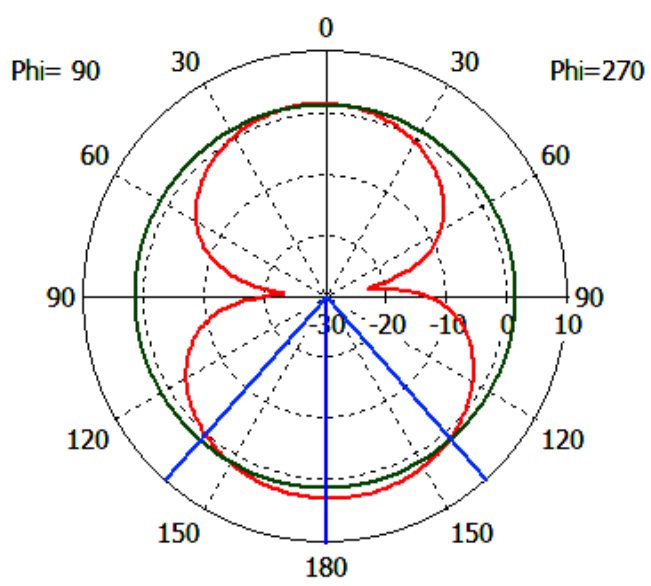

Theta / Degree vs. dBi 
Farfield Directivity Abs (Phi $=90)$

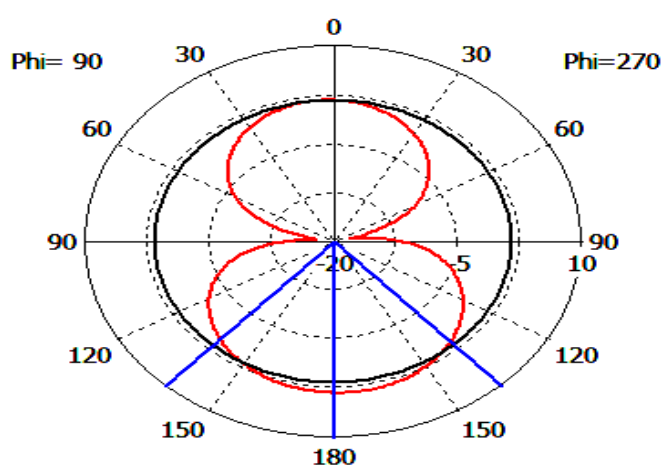

Theta / Degree vs. dBi

Figure 5: Radiation Pattern for frequency 3.5, 4.3 respectively.

The realized gain vs. frequency plot are shown figure 6 with maximum $5 \mathrm{db}$ at $12 \mathrm{Ghz}$ and minimum $0.3 \mathrm{~dB}$ and $-5 \mathrm{~dB}$ at 10 and $2 \mathrm{GHz}$ respectively.

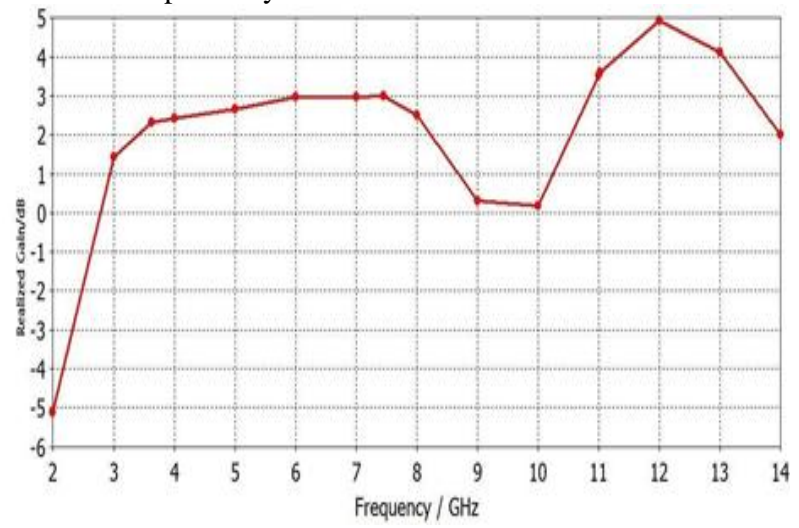

Figure 6: Realized Gain vs. Frequency plot

\section{CONCLUSION}

The paper describes Microstrip patch antenna that consists of a half circular patch which is extended to an extra length and is fabricated on FR-4 material that uses Microstrip feeding line method for feeding. A circular shape partial ground plane is used with an elliptical notch just below the feed line. The simulation results show that the antenna fulfills the requirement of UWB antenna operating in 3.1$10.6 \mathrm{GHz}$ and cover 3 to $12 \mathrm{GHz}$ range that covers the UWB range. The proposed antenna structure's simulation is carried out using the CST software. The Simulated results are presented, showed the usefulness of the proposed antenna structure for UWB applications and showing the good return loss and radiation patters in the interested UWB. This technique should be e investigated to reduce the size of the UWB antennas to suit more measured applications.

\section{ACKNOWLEDGMENTS}

I would like to evince a deep sense of gratitude to admirable Mr. Ajay Dadhich, Assistant Professor in Govt. Engineering College Ajmer and Mr. Prasant Singodiya Assistant Professor in Bhagwant University, Ajmer for providing us with best facilities and his timely suggestions. My special thanks to $\mathrm{M}$ Tech colleagues Chandraveer Singh and Danish Hayat for his help, cooperation and encouragement.
6. REFERENCES

[1] "Design and Analysis of Microstrip Antenna for UWB Applications" Kumar, Dhunish (2014) Design and Analysis of Microstrip Antenna for UWB Applications. M.Tech thesis.

[2] Deschamps, G.A., "Microstrip Microwave Antennas", Third symposium on the USAF Antenna Research and development program, University of IIInois, Moticello, IIInois, October 18-22, 1953.

[3] Bernhard, J.T., Mayes, P.E., Schaubert, D., and Mailoux, R.J.,'A commemoration of Deschamps' and Sichak's 'Microstrip Microwave Antennas': 50 years of Development, divergence, and new directions," Proceedings of the 2003 Antenna Applications Symposium, Moticello, IIInois, September 2003, pp. 189-230.

[4] Randy Bancroft, 2nd edition,"Microstrip and Printed Antenna Design".

[5] Gutton, H., and Baissinot, G., "Flat aerial for ultrahigh frequencies," French Patent no. 703113, 1955.

[6] Barret, R. M., "Microwave printed Circuits-a historical survey," IEEE Transactions on microwave Theory and techniques, vol.3, No.2, pp. 1-9.

[7] Denlinger, E.J., "Radiation from Microstrip Radiators" IEEE Transactions on microwave Theory and techniques, April1969, vol.17, No. 4, pp. 235-236.

[8] IEEE Transactions on antenna and propagation, January 1981.

[9] Constantine A. Balanis "Antenna Theory Analysis and Design" 3rd edition.

[10] Microstrip patch Antenna Antenna-theory.com

[11] John D. Karus \& Ronald J. Marhefka "Antenna for all applications" $3^{\text {rd }}$ edition

[12] Kobayashi, H., et al., "Flexible Microstrip Patch Applicator for Hyperthermia"

[13] Electromagnetics or microwave engineering ww.emtalk.com.

[14] H. Nornikman, F. Malek, "Design of Rectangular Stacked Patch Antenna with Four L-Shaped Slots and CPW-Fed for WiMAX Application" 2013 3rd International Conference on Instrumentation, Communications, Information Technology, and Biomedical Engineering (ICICI-BME) 39 Bandung, November 7-8, 2013.

[15] Vishwakarma, R.K., Verma, K.K., "Electromagnetically Coupled Square Microstrip Antenna for Dual-Band Operation" Communication Systems and Network Technologies (CSNT), 2013 International Conference 68 April 2013 Gwalior. 